\title{
Research on the Application of Sustainable Design in 3D Animated Characters__ A Case study of budding bear
}

\author{
Yang $\mathrm{Cui}^{{ }^{*}}$ \\ ${ }^{1}$ School of Visual Arts and Design The Guangzhou Academy of Fine Arts Guangdong Province, China
}

\begin{abstract}
This topic with the examples of budding bear series guided by the sustainable design, in the three dimensional animation role in comprehensive analysis comparison, induction and summary, hope through sustainable design to promote the role of the three dimensional animation application and development, under the three dimensional animation role in sustainable design of artistic expression and innovation concept, for the application of sustainable design in the three dimensional animation role study provide theoretical basis. This article first budding bear series $3 \mathrm{~d}$ animation, for example, analysis of sustainable design in the application of the three dimensional animation role, introduce bud bear series animation content, sustainable design were discussed from the six aspects of artistic expression in the three dimensional animation artistic expression, study plants, animals, machinery and other types of $3 \mathrm{~d}$ animation role type design; Finally, it summarizes the advantages and limitations of sustainable design in the application of 3D animated characters, lists the research cases of sustainable design in the application and innovation of 3D animated characters, and makes a comparative analysis with the series of works of Budding Bear.
\end{abstract}

\section{$13 \mathrm{~d}$ animation character theory}

This chapter simply sorts out the concepts and ideas of 3D animation and 3D animation characters, arranges and summarizes the origin and history of sustainable design in $3 \mathrm{D}$ animation characters, and analyzes the characteristics and expression techniques of 3D animation characters, including anthropomorphic techniques and exaggeration techniques. This paper is a systematic understanding of the role of $3 \mathrm{~d}$ animation, the integration of sustainable design to find common ground.

\subsection{The concept of $3 \mathrm{~d}$ animation}

Animation is a kind of comprehensive art. In the early stage, traditional $2 \mathrm{D}$ animation realized creative expression by exaggeration, while $3 \mathrm{D}$ animation innovated with realism and advanced visual effects. The most important story-telling carrier in 3D animation works is $3 \mathrm{~d}$ animation characters, who have their own unique styles in presentation and application.

In 1984, American animator John Lasseter produced a short 3D animation of "Fear of the Bee" in Industrial Light and Magic Studio, and in 1986, he and Pixar produced a $3 \mathrm{D}$ animation of " Luxo $\mathrm{Jr} " .3 \mathrm{~d}$ animation is not limited to human images, but opens up a lot of space for imagination. The diversity and richness of its characters promote the continuous development of $3 \mathrm{D}$ animation. With the development of social life, people in modern society have gradually penetrated into the idea of sustainable design in the application and creation of 3D animation characters, and injected the idea of satisfying the future ecology and circulation aesthetics into the creation and application of animation characters to convey profound ideological connotation and philosophical implication.

According to the search results, with " sustainable design * 3D animated characters" as the main subject search keywords, various literature searches on CnKI were blank. Meanwhile, the search for "Sustainable Design * 3D Animated characters" in foreign language is also blank. If sustainable design is searched separately, it can be found that sustainable design involves architectural design, industrial design, environmental art design and other fields, as well as bionics and ecology, etc., which is a new design trend and concept. Therefore, this shows the innovation and necessity of this research. How to extract the essence of $3 \mathrm{~d}$ animated characters through sustainable design has become the focus of our research. Among them, the excellent domestic animation Series " Budding Bear" is one of the best references for research, and its works have novel style characteristics for the application of the concept of sustainable use.

$3 \mathrm{D}$ animation also becomes $3 \mathrm{D}$ animation, which is different from the traditional animation creation mode. 3D animation is a kind of animation presentation mode that USES computer equipment to create three-dimensional images. In the use of virtual technology, the animation model and scene content are constructed to realize the adjustment of motion and parameters and achieve the presentation of artistic effects. 


\subsection{The concept of $3 \mathrm{~d}$ animated characters}

Animated characters belong to one of the artistic modeling, through exaggeration, personification and other methods of artistic modeling performance, for the animation character into the soul. As an important part of the field of 3D animation, 3d animated characters are designed and visually presented according to the script content. The design of 3D animated characters is a reflection of reality, higher than reality, and reflects people's spiritual pursuit. 3D animated characters are a kind of creative artistic expression of images.

\subsection{Sustainable design in the origins and history of 3D animated characters}

Sustainable design concept is derived from the western design, sustainable design process takes on the design and application practice in China, the related design is widely applied in architecture design and product design, and other fields, in fact the sustainable idea brings the certain effect for other domains, the three dimensional animation role brought the idea of sustainable design, design thinking and application method, however, were not organizing system, lack of internal anatomy study. Therefore, the innovation of this paper lies in: this paper analyzes the different artistic expression of the previous 3D animation characters with the thinking of sustainable design, and deeply understands the embodiment of sustainable design in 3D animation characters. Using sustainable design thinking to analyze the application methods and ideas hidden under the surface of $3 \mathrm{~d}$ animation characters, a more innovative theoretical framework is sorted out.

The three dimensional animation from 1995 to 2000 years for the initial stage of embryonic development important representative works include Disney' s " Snow White", pixar' s " toy story " and so on, the three dimensional animation role mainly focused on the story of the application of creative design, from 2001 to 2003, the three dimensional animation into the golden period of development, appeared the monsters, inc. " , " finding nemo ", such as thinking of nature and human in the problem of the relationship between the environment, and to explore emerging, animated characters of design application to start looking for similarities with the integration of human and nature. Since 2004, the visual expression of 3D animation has become more diversified, and the concept of sustainable design has been indirectly integrated into the design and application of characters, which contains the concept of cultural sustainability.

\subsection{The application of three - dimensional animation character expression}

The three dimensional animation role is the creation of the external image and internal spiritual sublimation, according to the requirements of the script content and proportion of ideas emotions for role modeling, design style, personality characteristics, colour collocation comprehensive factors such as creation, technique of expression such as exaggeration, personification, personalized, realistic and shape the characteristics of feeling, together constitute the whole content of the three dimensional animation.

\subsection{Domestic research status analysis}

Since the 20th century, the three dimensional animation is influenced by foreign development, produced such as " journey to the west of the return of another, " bears ", such as excellent animation, promote the development of application and practice of the three dimensional animation role, injection of elements and design more and more rich, however, the lack of sustainable design in theory to study the role of the three dimensional animation system.

\subsection{Analysis of foreign research status}

Dreamworks use $3 \mathrm{~d}$ software in 2001 made shrek, adopt unique $3 \mathrm{~d}$ character animation cartoon image of innovative applications, production of "finding nemo" in 2003 , the use of the return to natural biological image used in the design of characters, reflects the concept of sustainable design, the elements in the natural environment and the three dimensional animation role integration, a role of new traits.

\subsection{Advantages and limitations of sustainable design in the application of 3D animated characters}

(a) The advantages of sustainable design in the application of $3 D$ animation characters: Sustainable design is widely used in $3 \mathrm{~d}$ animated characters, systematizing and theorizing the characters' characteristics and artistic expression. In-depth analysis of excellent 3D animation character cases, clear the design type of 3D animation character under the concept of sustainable design, give the character more vitality and creativity.

(b) Limitations of sustainable design in character design in 3D animation: The application of sustainable design in the three dimensional animation role in had not complete system, many aspects of the research need to constantly improve, this topic is budding bear series of research and application of the animated characters around the key role in design and the character of different aspects of artistic expression, deep research scope to lay a solid foundation for the future.

\section{Chapter 3 takes budding bear as an example to analyze the application of sustainable design in 3D animated characters}

This chapter from the three dimensional animation role natural fusion point, cultural needs, emotional force, intelligent technology, color joint degrees, image type six aspects and analyses the influence of sustainable design " 
bud bear" series the profound artistic expression of the three dimensional animation works, through the emotional, cultural, color, etc sums up the concept of sustainable design. Let the audience experience the charm and character of sustainable design through animation.

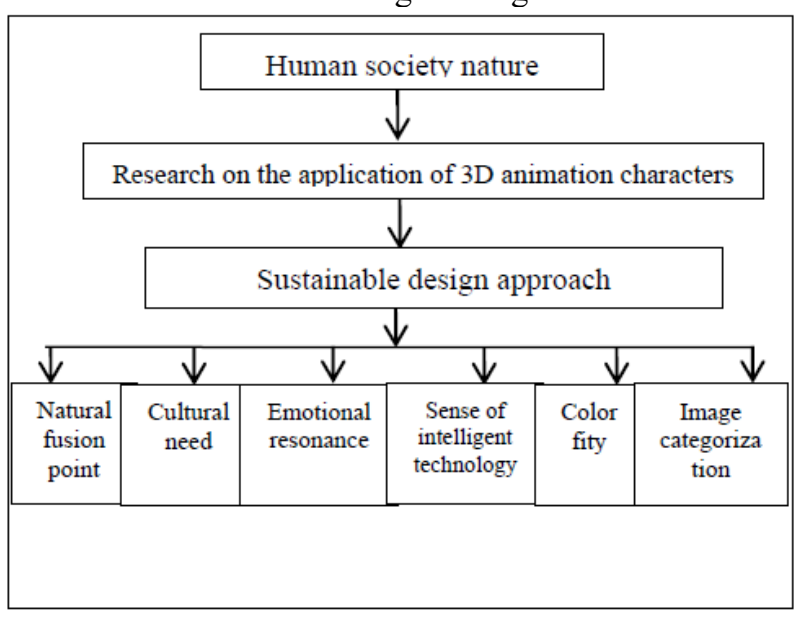

Fig1. Example of a figure caption.

\subsection{Sustainable design enhances the natural fusion of $3 \mathrm{~d}$ animated characters}

Sustainable design improves the relationship between human and nature of $3 \mathrm{~d}$ animation characters, and increases the concept of sustainable environmental protection through natural fusion points. " Bud bear " series animation, for example green shoots bear the image of the inspiration from fleshy plants, seed bear's image as a role in the shape of meaty plant overall image, associated with the natural things in People' s Daily life, the head of the buds represents the germination of life, also represents the emergence of new forces, is the starting point of life, at the same time, the plants grow in the soil need to water the soil fertilizer applied natural philosophy makes the three dimensional animation character budding bears a fresh vitality and affinity, showing good vision of the human and the nature harmonious coexistence, embodies the concept of sustainable design in the implementation of the three dimensional animation role in the development of natural penetration, Promote the sustainable development of man and nature.

\subsection{Sustainable design sublimates the cultural needs of $3 d$ animation characters}

Sustainable design sublimates the cultural needs of $3 \mathrm{~d}$ animation characters, and the concise and profound natural and environmental culture satisfies people' $s$ demands for cultural development. The three-dimensional animation image of budding bear ADAPTS to the trend of sustainable design, changes its own image to adapt to the environment, follows the laws of nature, forms a combination of natural culture and modern culture, and subtly influences people' s behavior and spirit.

\subsection{Sustainable design enhances the emotional resonance of $3 \mathrm{~d}$ animated characters}

Sustainable design sublimates the cultural needs of $3 \mathrm{~d}$ animation characters and emotionally touches the hearts of the audience. The bud in bud bear bear and flower POTS are interdependent relationship, flowerpot is equivalent to the concept of " home ", and to the healthy growth of the bud bear also needs to have love and sunshine, the rain, like the growth of the human individual should be accompanied by family, health, environment, etc. , flower POTS and budding bear from the side Angle to convey the concept of sustainable design, by the reality and the perfect combination of the three dimensional animation audience's emotional resonance, the emotion into the role.

\subsection{Sustainable design fits the intelligent sense of technology of $3 \mathrm{~d}$ animation characters}

Sustainable design fit the role of the three dimensional animation intelligent technology development, with a virtual three-dimensional bud bear communicate with real keeper character dialogue, remind viewers to experience of modern science and technology equipment, bud bear the image of the interaction with people feel sense of freedom and openness, the three dimensional animation character budding bear head of green shoots as conditions change and change, through the reflection of this phenomenon for the natural environment, additional advanced role to return to the strength of the soil, let the audience feel smart interesting at the same time associated with the concept of sustainable.

\subsection{Sustainable design enriches the color fit of $3 d$ animated characters}

Sustainable design enriches the color fit of $3 \mathrm{~d}$ animated characters, and displays a harmonious and friendly environment through the use of natural colors. "Bud Bear "series of works mainly show the colors of plants. The color design of green and pink inspires people's yearning for a higher life and sustenance for environmental protection through the power of color.

\subsection{Sustainable design improves the variety of $3 d$ animation characters}

Sustainable design in the application of the three dimensional animation role the innovation of the research is divided into visual and tactile innovation, summarizes the symbolization in terms of thinking innovation, abstraction, functionalization of innovative thinking, to inject more animated characters appeal and imagination space, to open the $3 \mathrm{~d}$ character animation design train of thought, promote the further research of sustainable design in the field of animation role. 


\section{Taking sprout bear as an example to analyze the role type design of sustainable design in 3D animation}

Sustainable design integrates the role design of plants, animals, machines and other types, and sorts out the relevance of sustainable design from the artistic expression of their works and role type design. Sustainable design adds aesthetic value and philosophical connotation to the type design of $3 \mathrm{~d}$ animated characters and has important research significance and value. Analyze the designs of plants, animals, machines and other types of characters in the series of embryonic bear works. On the one hand, it conforms to the spiritual and cultural development demand for social sustainable development; on the other hand, it also improves and explores the theoretical research and exploration of sustainable design in $3 \mathrm{~d}$ animation character design. Therefore, it is necessary to study the application of sustainable design in the series of budding bears.

\subsection{Plant type character design}

Sustainable design improves the image types of $3 \mathrm{~d}$ animation characters and integrates sustainable meaning into character modeling. In the animation series " Sprout Bear ", the circular shape of sprout bear presents a full and rounded effect visually, giving people a kind and lovely impression, injecting inspirations for sustainable design cycle, and expressing the sustainable concept of maintaining ecological nature through design.

Sustainable design carries out plant type design for $3 d$ animation characters, and combines the harmonious and healthy sustainable design concept with unique symbolic roles, so that people can go deep into nature through character design and maintain the healthy development of society. For example, in the series of " Budding Bear ", the character image of cactus, which is resistant to drought and high temperature, comes from the soil and will eventually return to the soil, closely linking life and nature, and reflecting the profound connotation of sustainable design through the role design of plants.

\subsection{Animal type character design}

Sustainable Design Carries out animal type design for $3 \mathrm{~d}$ animation characters, and combines the sustainable design concept of natural feelings with friendly animal images. Bud Bear innovatively integrates the inspiration of green plants and the image of bear, communicates the desire of friendly animal and human contact and communication through the role, increases the unique connotation of sustainable design, and enables people to learn to integrate into nature and understand nature through the role design.

\subsection{Mechanical type character design}

Sustainable design Carries out mechanical type design for $3 \mathrm{~d}$ animation characters. Besides being used, mechanical equipment presents a positive interactive and lively effect in animation. The sustainable design is implanted into the character design of mechanical type, and people' s waste of mechanical products is reflected through the form of animation, so as to influence the audience to develop towards sustainable, green and environmental protection.

\subsection{Other types of character design}

Sustainable Design Carries out other types of design for $3 \mathrm{~d}$ animation characters, and diverges design thinking to make use of design for objects around. For example, in Sprout Bear, express delivery boxes and boxes are regarded as wastes. After sprout Bear's design, express boxes become small houses that can be kept warm for living, which endows the concept of sustainability to waste items.

\section{The enlightenment of sustainable design to the application research of 3D animation characters}

Sustainable design in the application of the three dimensional animation role the innovation of the research is divided into visual and tactile innovation, summarizes the symbolization in terms of thinking innovation, abstraction, functionalization of innovative thinking, to inject more animated characters appeal and imagination space, to open the $3 \mathrm{~d}$ character animation design train of thought, promote the further research of sustainable design in the field of animation role.

\subsection{Sustainable design practices innovation in $\mathbf{3 d}$ animated characters}

4.1.1 Visually innovative thinking: Sustainable sustainable design, environmentally sustainable, culture, catering to the needs of the human spiritual and cultural level, from the industrial revolution to the design of the information technology revolution period without considering the sustainable problem, not suitable for the change and development of society, every design update growth is also under the aesthetic thought of thinking of system, guide the participants to sustainable design with nature, relationship to build a link between the form of sustainable design and the design of the waste of resources is in stark contrast, the rich design realize the improvement of the aesthetic content and extension. The visual innovation enables sustainable design to penetrate into people' $s$ visual experience and viewing effect, infuse inspiration of aesthetics and design, and make $3 \mathrm{~d}$ animated characters full of vigor and vitality.

4.1.2 Creative thinking in touch: In the application of $3 \mathrm{D}$ animation characters, sustainable design is no longer limited to a single picture, but jumps from a single paper and screen to achieve interactive communication through the combination of real people and virtual people, which directly affects the psychological sense of the audience and generates a strong artistic appeal through the virtual and real interactive experience. Pig Fart series 3d 
animation combines virtual and real characters in the way of combining virtual and real people, which is refreshing.

Sustainable design is a kind of design method and design concept, focusing on improving people' s life quality. Sustainable design is not a single innovation and design of the material and structure of the design object, but the extension and expansion of the concept in a multi-field, allround and more extensive situation. This concept of sustainable design is applied to the design and application of $3 \mathrm{D}$ animated characters, and the reference value of innovative thinking in tactile sense is explored. The trend of sustainable production of $3 \mathrm{~d}$ animated character derivatives and the adoption of environment-friendly and energy- saving materials can not only meet people' $s$ spiritual needs but also reduce environmental pollution and resource waste, and promote new tactile experience.

\subsection{Sustainable design thinking innovation in 3D animated characters}

\subsubsection{Symbolic innovation: Sustainable design integrates} symbolic and innovative thinking in the three-dimensional role, and designs the role with the spiritual and cultural connotations of the sustainable concept, which has strong recognition and profound representativeness.

Different $3 \mathrm{~d}$ animation has its unique symbols, symbols with the three dimensional animation role unique decorative effect, whether it is the role of the three dimensional animation action, colour, costume design and other parts can use sign language different from other $3 \mathrm{~d}$ animated characters, making the three dimensional animation characters present a more powerful tension, symbolic innovation is not only the enrichment of sustainable concept, is also a visual representation of an ideal state of sustainable.

4.2.2 Abstract innovation: Sustainable design not only gives $3 \mathrm{~d}$ animation characters perceptual expression, but also USES scientific rational thinking to reflect on the characters and abstractly summarizes the sustainable concept, which is simply and concisely expressed in the design and application of the characters.

In the category of graphic language, it is divided into abstract, concrete and other properties. The innovation of $3 \mathrm{D}$ animated characters lies in the abstraction of character design by using the sustainable concept and injecting the concept of environmental protection and sustainability into it. Such as foreign outstanding $3 \mathrm{~d}$ animation " the sister and I the role of design, combined with the characteristics of exploration, Marine biology, environmental protection for the characters, the modelling of image using rounded lines, squares, triangles combination technique close to the person, the harmonious atmosphere, bold innovation point, line, below $3 \mathrm{~d}$ character animation with abstract thinking, convey the novel design idea and the cultural concept, nature, the sustainable concept into the modelling, colour, shaping of the emotional, rather than to simply use the technique of anthropomorphic animals shape, abstract innovative thinking is worth our learning.

4.2.3 Functional innovation: Sustainable design for the three dimensional animation role bring good visual experience, inner culture also shows its important function, the natural, ecological and environmental elements into the creation of animated characters, fully demonstrate the features of sustainable and creative thoughts, indirect promotion in the spirit of documented value national cultural soft power.

To some extent, sustainable design implies that the design of $3 \mathrm{~d}$ animated characters should consider the concept of environmental protection. Such as "The Octonauts " of The three dimensional animation role with The image of sea creatures, show a green, natural, health, knowledge learning function, The polar bear as The main method of image of buck captain, lead The team to explore The sea world, The importance of The polar bear for people with existing conditions, The polar bear in reality because of The trend of global warming survival crisis, also affect The environment of penguins, walruses and other Marine organisms, through The study of The sustainable idea of $3 \mathrm{~d}$ animation role of fusion, sustainable concept to convey to The audience, will influence people' s psychology and behavior, to reflect social waste phenomenon, Thus promoting sustainable development.

\section{5 conclusion}

In the new era with the continuous development of science, technology and economy, the integration, communication and reference of disciplines have become increasingly important. The application of 3D animation characters has always reflected the shadow of sustainable design, but there is a lack of systematic theoretical research and method induction. Through the classic three- dimensional image of the budding bear, the sustainable design concept is systematically recognized, and the influence range of sustainable design is found from the design of artistic expression and animation type.

This paper not only studies the application of sustainable design in $3 \mathrm{D}$ animation characters, but also makes a profound interpretation of the relationship between life, society and aesthetic design. This unique sustainable concept affects different levels of design in the research method of 3D animation characters. On the one hand, the sustainable concept caters to the social development and spiritual needs of the current era; on the other hand, the sustainable design constructs new design inspiration and design thinking in the application of $3 \mathrm{D}$ animation characters, which promotes the diversified application and development of 3D animation.

Sustainable design extends the three dimensional animation role of artistic expression, is to rethink of applied research for $3 \mathrm{~d}$ characters, through the concept of sustainable design of $3 \mathrm{~d}$ animated characters into the art form of sustainable development, promote the green spirit, break the barrier of the application in the field of 
sustainable design in animation, the sustainable design aesthetic and spiritual into the three dimensional animation role, make the three dimensional animation more energetic and expressiveness, is conducive to develop sustainable design in art in the application of the three dimensional animation character value, rich animation creation of combining with the research and application of the theory and practice of create invisible spiritual and cultural value for society, It provides some references and design ideas for other related fields and further promotes the application research of $3 \mathrm{D}$ animation characters.

\section{Acknowledgment}

This paper aims to sort out the relevance of sustainable design from the artistic expression of the works and the character type design by analyzing the excellent $3 \mathrm{~d}$ animated characters at home and abroad and focusing on the works of budding bear. Sustainable design adds aesthetic value and philosophical connotation to the application of $3 \mathrm{~d}$ animated characters, which has important research significance and value.

\section{References}

1. Chei-Chang Chiou, Li-Chu Tien, Li-Tze Lee Effects on learning of multimedia animation combined with multidimensional concept maps[J], 2015, 80

2. The Application of Virtual Reality Technology in Film and Television Animation Design in the New Media Age[A]. Du Chan. Proceedings of 2019 3rd Scientific Conference on Mechatronics Engineering and Computer Science (SCMC 2019) [C]. 2019

3. An Analysis of the Production Methods of Interactive Animation Special Effects in Visual Communication Design[A]. $\mathrm{Xu}$ Gao. Proceedings of 2019 International Conference on Humanities, Cultures, Arts and Design (ICHCAD 2019) [C]. 2019

4. Construction of Regional Cultural Dimension of Chinese Animation Creation in the Context of Cultural Globalization[A]. Xiaona Ma. Proceedings of 2019 9th International Conference on Social Science and Education Research (SSER 2019) [C]. 2019

5. Sooksan Kantabutra, Nuttasorn Ketprapakorn Toward a theory of corporate sustainability: A theoretical integration and exploration[J].Journal of Cleaner Production, 2020 